\title{
Acute morphine alters GABAergic transmission in the central amygdala during naloxone-precipitated morphine withdrawal: role of cyclic AMP
}

\author{
Michal Bajo $^{1 *}$, Samuel G. Madamba ${ }^{1}$, Marisa Roberto ${ }^{1}$ and George R. Siggins ${ }^{2}$ \\ ${ }_{1}$ Committee on the Neurobiology of Addictive Disorders, The Scripps Research Institute, La Jolla, CA, USA \\ ${ }^{2}$ Department of Molecular and Cellular Neuroscience, The Scripps Research Institute, La Jolla, CA, USA
}

\section{Edited by:}

Sidney A. Simon, Duke University, USA

\section{Reviewed by:}

Hao Zhang, Pfizer Neuroscience, USA

Mark S. Brodie, University of Illinois at Chicago, USA

\section{${ }^{*}$ Correspondence:}

Michal Bajo, Committee on the Neurobiology of Addictive Disorders, The Scripps Research Institute, 10550 North Torrey Pines Road, SP30-1150, La Jolla, CA 92037, USA e-mail:mbajo@scripps.edu
The central amygdala ( $\mathrm{CeA}$ ) plays an important role in opioid addiction. Therefore, we examined the effects of naloxone-precipitated morphine withdrawal (WD) on GABAergic transmission in rat $\mathrm{CeA}$ neurons using whole-cell recordings with naloxone in the bath. The basal frequency of miniature inhibitory postsynaptic currents (mIPSCs) increased in CeA neurons from WD compared to placebo rats. Acute morphine $(10 \mu \mathrm{M})$ had mixed effects $(\geq 20 \%$ change from baseline) on mIPSCs in placebo and WD rats. In most CeA neurons (64\%) from placebo rats, morphine significantly decreased mIPSC frequency and amplitude. In $32 \%$ of placebo neurons, morphine significantly increased mIPSC amplitudes but had no effect on mIPSC frequency. In WD rats, acute morphine significantly increased mIPSC frequency but had no effect on mIPSC amplitude in $41 \%$ of CeA neurons. In $45 \%$ of cells, acute morphine significantly decreased mIPSC frequency and amplitude. Pre-treatment with the cyclic AMP inhibitor (R)-adenosine, cyclic 3', $5^{\prime}$-(hydrogenphosphorothioate) triethylammonium (RP), prevented acute morphine-induced potentiation of mIPSCs. Pre-treatment of slices with the Gi/o G-protein subunit inhibitor pertussis toxin (PTX) did not prevent the acute morphine-induced enhancement or inhibition of mIPSCs. PTX and RP decreased basal mIPSC frequencies and amplitudes only in WD rats. The results suggest that inhibition of GABAergic transmission in the CeA by acute morphine is mediated by PTX-insensitive mechanisms, although PTX-sensitive mechanisms cannot be ruled out for non-morphine responsive cells; by contrast, potentiation of GABAergic transmission is mediated by activated cAMP signaling that also mediates the increased basal GABAergic transmission in WD rats. Our data indicate that during the acute phase of WD, the CeA opioid and GABAergic systems undergo neuroadaptative changes conditioned by a previous chronic morphine exposure and dependence.

Keywords: opioids, dependence, GABA, G-protein, cAMP, withdrawal, morphine

\section{INTRODUCTION}

The central nucleus of the amygdala (CeA) is a part of the neuroanatomical entity termed the extended amygdala that also includes the bed nucleus of the stria terminalis (BNST), and a transition zone in the medial (shell) subregion of the nucleus accumbens (Heimer and Alheid, 1991). The extended amygdala is considered a common anatomical substrate integrating brain arousal-stress systems with hedonic processing systems producing the emotional states that promote negative reinforcement mechanisms associated with the development of addiction (Koob and Volkow, 2010). In addition, the extended amygdala has long been hypothesized to play a key role in the emotional component of pain processing (Neugebauer et al., 2004), and in the mediation of the affective signs of withdrawal from acute morphine treatment (Criner et al., 2007) and the motivational aspects of chronic opiate withdrawal (Frenois et al., 2002). The CeA has a key function in the acute reinforcing actions of drugs of abuse, including opioids (Koob and Volkow, 2010), and is considered to be critical for the affective component of acute and chronic opiate withdrawal (Jin et al., 2004).

Our recent study and those from others have shown that not all CeA neurons are responsive to acute opioids, suggesting the presence of neuronal subpopulations mediating the opioid effects in the CeA (Zhu and Pan, 2004, 2005; Finnegan et al., 2005, 2006; Chieng et al., 2006; Bajo et al., 2011). Most CeA neurons in rodents are GABAergic neurons with inhibitory recurrent or feed-forward connections, as well as inhibitory projections to brainstem (Sun and Cassell, 1993; Cassell et al., 1999) and other extended amygdala areas such as BNST (Weller and Smith, 1982; Veinante and Freund-Mercier, 1998). Activation of opioid receptors is reported to induce inhibitory potassium currents in subpopulations of CeA neurons characterized by expression of $\mathrm{mu}$ (MORs) and kappa (KORs) opioid receptors (Zhu and Pan, 2004; Chieng et al., 2006). 
MORs tonically inhibit GABAergic transmission in the CeA and acute activation of MORs diminishes GABAergic transmission in most CeA neurons, predominantly by reducing presynaptic GABA release (Kang-Park et al., 2009; Bajo et al., 2011). Moreover, in the CeA neurons projecting to periaqueductal gray area (PAG), presynaptic MORs primarily attenuate GABAergic synaptic transmission (Finnegan et al., 2005). In the central extended amygdala chronic morphine induces transcriptional plasticity characterized by a dysregulation of expression of genes involved in neurogenesis, cell growth and signaling (Bajo et al., 2006; Befort et al., 2008). Heroin self-administration alters gene expression of opioids in the CeA (Solecki et al., 2009). In amygdala, chronic heroin administration decreases opioid agonist-stimulated GTP binding but does not alter MOR binding autoradiography (Sim-Selley et al., 2000; Maher et al., 2005). In contrast, no changes in the GTP binding have been observed in amygdala after chronic morphine (Sim et al., 1996) or in the CeA during morphine withdrawal (Kirschke et al., 2002). The ERK signaling pathway in the CeA is critical in induction of morphine craving (Li et al., 2008). We previously found no significant effect on basal GABAergic transmission during chronic morphine treatment, suggesting a lack of effect of long-term morphine, or tolerance and alterations of MOR-dependent postsynaptic mechanisms (Bajo et al., 2011).

Repeated morphine-conditioning treatment enhances glutamate synaptic strength and recruits new functional DORs on glutamate synapses in the CeA (Sim et al., 1996; Sim-Selley et al., 2000; Kirschke et al., 2002; Maher et al., 2005; Befort et al., 2008; Li et al., 2008; Bie et al., 2009; Solecki et al., 2009). These findings indicate that chronic opioid exposure followed by subsequent withdrawal induces complex neuroadaptation of the opioid and other systems in the CeA. The mechanisms mediating such adaptive changes likely involve both pre- and postsynaptic mechanisms and lead to alteration of MOR-dependent modulation of the physiological and synaptic properties of the amygdala neurons.

In a previous study (Bajo et al., 2011) characterizing adaptation of the GABAergic system during continuous chronic morphine exposure we found a tolerance to inhibitory effects of acute activation of MORs on presynaptic GABA release in the CeA. Moreover, we found very similar effects of acute application of MOR agonist and antagonist on GABAergic transmission in placebo- and morphine-treated rats, further suggesting a homeostatic neuroadaptation of the CeA opioid system and MOR-dependent regulation of CeA GABAergic transmission. Interestingly, we observed significant effects of acute MOR agonist on the mIPSC amplitudes only in CeA of morphinetreated rats, but not of placebo rats, suggesting postsynaptic adaptative changes of the MOR system during chronic morphine treatment (Bajo et al., 2011). Therefore, in the present study, we aimed to assess the changes of the MOR-dependent modulation of GABAergic transmission associated with an early phase of morphine withdrawal. We hypothesized that, as in other brain regions (Christie, 2008), the CeA opioid system will be over-activated during morphine withdrawal. Therefore, here we have examined basal CeA GABAergic transmission during morphine withdrawal and challenged the MOR system by acute morphine application to examine the influence of activated MORs on GABAergic transmission at a withdrawal time-point. To model naloxone-precipitated morphine withdrawal, we performed all recordings with naloxone (placebo rats) and naloxone plus morphine co-application (morphine WD rats) in the bath solution. In the ventral tegmental area Madhavan et al. (2010a) found an acute morphine-induced facilitation of GABAergic transmission, indicating a switch in the coupling of MORs from inhibitory Gi/o subunit to stimulatory Gs subunit signaling. These findings are in accord with our preliminary report on the facilitatory effects of acute morphine application on CeA GABAergic transmission during spontaneous morphine withdrawal (Bajo et al., 2008, 2009). Thus, we hypothesized that adaptative changes of MOR and GABAergic systems similar to those reported by Madhavan et al. are present in $\mathrm{CeA}$ during naloxone-precipitated morphine withdrawal.

Our results show alterations of the basal GABAergic transmission in morphine WD rats, and acute morphine-induced increases and decreases of CeA GABAergic transmission in both placebo and WD rats. Furthermore, as Gi/o are the primary G subunits coupled to MORs (Laugwitz et al., 1993; Clark et al., 2006), we hypothesized that inhibitory effects of acute morphine application on CeA GABAergic transmission are mediated by Gi/o, whereas the facilitatory effects of acute morphine involve Gs subunits and activation of cAMP-PKA signaling. To test this hypothesis, we applied pertussis toxin (PTX), an inhibitor of Gi/o subunits, and (R)-adenosine, cyclic $3^{\prime}, 5^{\prime}$-(hydrogenphosphorothioate) triethylammonium (RP), an inhibitor of the cAMP-PKA pathway. We found that PTXinsensitive mechanisms are involved in the acute morphineinduced inhibition of GABAergic transmission, but we cannot completely rule out an involvement of PTX-sensitive mechanisms in the inhibitory effects of acute morphine. However, activated CAMP signaling appears to mediate the morphine withdrawal-elicited increase of basal GABAergic transmission and the acute morphine-induced facilitation of GABAergic transmission in CeA.

\section{MATERIALS AND METHODS ANIMAL TREATMENT}

Male Sprague-Dawley rats (weights at the time of electrophysiological recordings: placebo: $218 \pm 8 \mathrm{~g} ; n=25$; morphine: $216 \pm$ $11 \mathrm{~g} ; n=24)$ were housed in a temperature- and humiditycontrolled room on a 12-h light/dark cycle (lights on at 6:00 am) with food and water available ad libitum. We used the standard morphine pellet method, with two morphine $(75 \mathrm{mg}$ of morphine/pellet) or placebo pellets implanted subcutaneously (Gold et al., 1994; Bajo et al., 2011). To precipitate morphine withdrawal, we injected naloxone $(1 \mathrm{mg} / \mathrm{kg})$ subcutaneously. Just prior to sacrifice, the rats were then observed for development of physical signs of morphine withdrawal, represented by diarrhea and wet dog shakes. These signs developed solely in chronic morphine-treated rats within 15-20 min after the naloxone injection. We conducted all care and surgical procedures in accordance with the National Institutes of Health Guide for the Care and Use of Laboratory Animals and with the Institutional Animal Care 
and Use Committee (IACUC) policies of The Scripps Research Institute.

\section{SLICE PREPARATION}

Rats were anesthetized with $3 \%$ isoflurane, decapitated and the brains quickly removed and placed in ice-cold oxygenated artificial cerebrospinal fluid (ACSF; in mM: $130 \mathrm{NaCl}, 3.5 \mathrm{KCl}, 1.25$ $\mathrm{NaH}_{2} \mathrm{PO}_{4} \cdot \mathrm{H}_{2} \mathrm{O}, 1.5 \mathrm{MgSO}_{4} .7 \mathrm{H}_{2} \mathrm{O}, 2.0 \mathrm{CaCl}_{2} .2 \mathrm{H}_{2} \mathrm{O}, 24 \mathrm{NaHCO}_{3}$, and 10 glucose) gassed with $95 \% \mathrm{O}_{2}$ and $5 \% \mathrm{CO}_{2}$. We cut coronal slices $(300-400 \mu \mathrm{M})$ containing the CeA using a Leica $1000 S$ vibrotome cutter (Campden, Lafayette, Indiana). To simulate in vivo conditions of naloxone-induced withdrawal during our recordings in morphine dependent rats, we included naloxone $(10 \mu \mathrm{M})$ and morphine $(1 \mu \mathrm{M})$ in the cutting solution during slice preparation and in the bath during recordings. The slice preparation and recordings from placebo (morphine naïve) rats were conducted in the ACSF containing naloxone $(10 \mu \mathrm{M})$. We performed recordings within $1-6 \mathrm{~h}$ after slice cutting. Drugs were added to the ACSF from stock solutions (flow rate $2-4 \mathrm{ml} / \mathrm{min}$ ) in known concentrations and we took all physiological measures before acute morphine (baseline) and during its superfusion (5$15 \mathrm{~min})$. To avoid multiple morphine applications, we recorded from a single neuron from each slice and discarded all other slices exposed to acute morphine.

\section{WHOLE-CELL PATCH-CLAMP RECORDING}

We performed whole-cell patch-clamp recording in voltage clamp mode as described previously (Bajo et al., 2011). To facilitate cell identification, we used infrared/DIC visualization, followed by digitization and image enhancement, via an upright, fixedstage Olympus microscope. We used a 40X water immersion lens and image processing with EXI Blue CCD camera (QImaging software, Surrey, BC, Canada). We isolated miniature $\mathrm{GABA}_{\mathrm{A}}$ IPSCs (mIPSCs) pharmacologically by applying $20 \mu \mathrm{M}$ DNQX, $30 \mu \mathrm{M}$ DL-AP5, and $1 \mu \mathrm{M}$ CGP 52432 and $1 \mu \mathrm{M}$ tetrodotoxin (TTX) to the bath. To evaluate a role for Gi/o and cAMP, we pre-treated CeA slices with $250 \mathrm{ng} / \mathrm{ml}$ of PTX for 0.5 up to $6 \mathrm{~h}$, an inhibitor of Gi/o subunits, and $500 \mathrm{nM}(\mathrm{R})$-adenosine, cyclic $3^{\prime}, 5^{\prime}$-(hydrogenphosphorothioate) triethylammonium (RP), an inhibitor of cAMP signaling, for $15 \mathrm{~min}$ prior to and throughout the recordings. All mIPSC recordings were held at $-60 \mathrm{mV}$ membrane potential and were made with 3-4 M $\Omega$ pipettes filled with an internal solution containing (in $\mathrm{mM}$ ): $135 \mathrm{KCl}$, 10 HEPES, $2 \mathrm{MgCl}_{2}, 0.5$ EGTA, 5 ATP, and 1 GTP (the latter two added fresh on the day of recording), $\mathrm{pH}$ 7.3-7.4, osmolarity $275-290 \mathrm{mOsm}$. For data acqusition, we used a Multiclamp 700B (Molecular Devices) and pClamp 10.2 software (Molecular Devices).

\section{DATA ANALYSIS AND STATISTICS}

To analyze data acquired from whole-cell recordings, we used Clampfit 10.2 (Molecular Devices) and MiniAnalysis 5.1 software (Synaptosoft, Leonia, NJ), respectively. We used GraphPad Prism 5.0 software (GraphPad Software, San Diego, CA) for all statistical analyses of results obtained by intracellular and whole-cell recordings. Because not all CeA neurons are responsive to MOR agonists (Zhu and Pan, 2004; Chieng et al., 2006), we used a change of $20 \%$ of control values as a threshold for dividing the cells into MOR agonist-sensitive and -insensitive groups (Bajo et al., 2011). We accepted statistical significance at the $p<0.05$ level using One- and Two-Way ANOVA, the Kolmogorov-Smirnoff test, and $t$-tests.

\section{DRUGS}

We purchased CGP 55845A, DNQX, DL-AP5, and PTX from Tocris Biosciences (Ellisville, MI), TTX from Calbiochem (San Diego, CA) and RP from Sigma-Aldrich (St. Luis, MO). Morphine sulphate, morphine, and placebo pellets were provided by the National Institute on Drug Abuse.

\section{RESULTS}

\section{EFFECTS OF MORPHINE AND OPIATE WITHDRAWAL}

We recorded miniature IPSCs from 76 CeA neurons using wholecell recordings in voltage-clamp mode. The basal frequencies of the CeA mIPSCs were significantly $\left[t_{(52)}=3.1, p<0.01\right]$ increased in the morphine withdrawn (WD) rats $(0.9 \pm 0.1 \mathrm{~Hz}$, $n=29)$ compared to the placebo rats $(0.5 \pm 0.1 \mathrm{~Hz}, n=25)$, suggesting an increase in presynaptic GABA release during naloxone-precipitated WD. There was no significant difference in the mean mIPSC amplitudes between the CeAs of placebo $(57.9 \pm 3.6 \mathrm{pA}, n=25)$ and morphine WD rats $[65.6 \pm 3.5 \mathrm{pA}$, $n=29 ; t_{(52)}=1.8, p>0.05$; Figure 1].

Acute application of morphine $(10 \mu \mathrm{M})$ produced mixed effects on the mIPSC frequencies and amplitudes in both placebo and morphine WD rats. We used a $20 \%$ change in the frequencies and/or amplitudes of the mIPSCs as the selection criterion (Bajo et al., 2011) and divided the CeA neurons into three groups: no response, increase, or decrease in the mIPSC measures. In placebo rats, the majority of CeA neurons (16 of 25 neurons) responded to acute superfused morphine with a decrease in both frequency [ $73.0 \pm 4.3 \%$ of baseline; $t_{(15)}=2.4$, $p<0.05]$ and amplitude $\left[81.4 \pm 2.9 \%\right.$ of baseline; $t_{(15)}=5.4$, $p<0.05$ ] of the mIPSCs (Figures 2A-C,G,H). Another subpopulation (8 of 25 neurons) of placebo CeA neurons responded to acute morphine application with a significant increase in the amplitude [122.3 $\pm 7.8 \%$ of baseline, $\left.n=8 ; t_{(7)}=3.7, p<0.05\right]$ but not frequency of mIPSCs [129.2 $\pm 9.0 \%$ of baseline, $t_{(7)}=$ 1.8, $p>0.05$; Figures 2D-H]. In the morphine WD rats, acute morphine application decreased both frequency $[71.0 \pm 4.2 \%$ of baseline, $n=13 ; t_{(12)}=4.2, p<0.05$ ] as well as amplitude $\left[86.2 \pm 3.8 \%, t_{(12)}=3.3, p<0.05\right]$ of the mIPSCs in 13 of 29 CeA neurons. Another subpopulation of the CeA neurons (12 of 29 cells) responded to acute morphine with a significant increase in the frequency $\left[163.9 \pm 18.6 \%, n=12 ; t_{(11)}=3.3\right.$, $p<0.01]$ but not the amplitude of mIPSCs [116.8 $\pm 13.3 \%$, $t_{(11)}=1.3, p>0.05$; Figures 2D-H]. Two-Way ANOVA, comparing the enhancing effects of acute morphine on the mIPSC frequencies between CeA neurons from placebo and morphine pellet treated and WD rats, showed significant main effects of acute morphine application $\left[F_{(1,18)}=10.8, p<0.01\right]$ and pellet treatment $\left[F_{(1,18)}=7.9, p<0.01\right]$, and no significant interaction between acute morphine and pellet treatment $\left[F_{(1,18)}=\right.$ $3.5, p=0.08]$. The ANOVA analysis also showed a significant main effect of acute morphine $\left[F_{(1,18)}=5.9, p<0.05\right]$ but no 


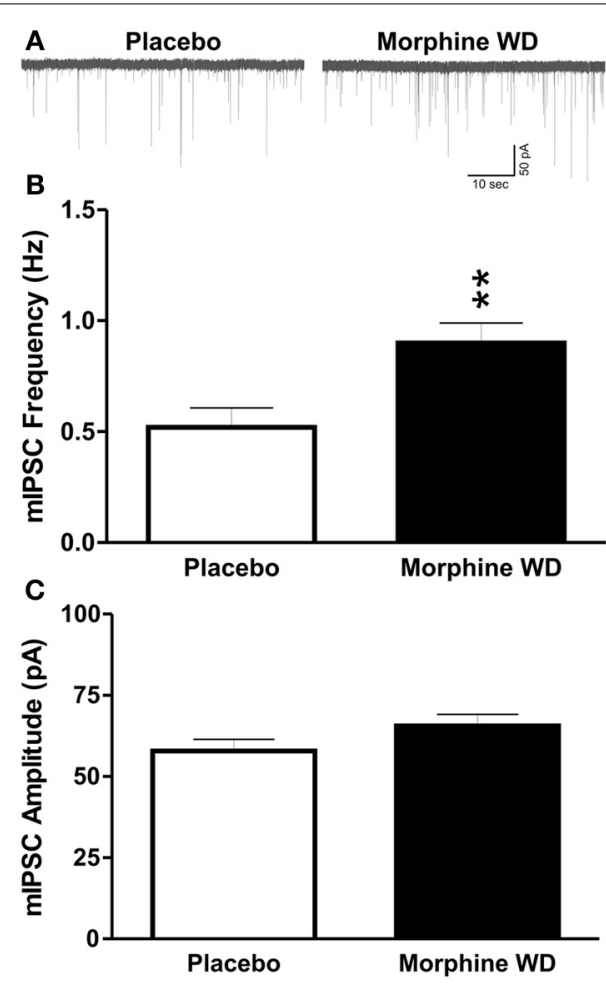

FIGURE 1 | Naloxone-precipitated withdrawal increases GABA release in the $\mathrm{CeA}$ from morphine-dependent rats. (A) Representative $\mathrm{GABA}_{A}$ mIPSC recordings (in the presence of TTX) from CeA neurons from placebo (left column) and morphine-withdrawn rats (right column), respectively. (B) The mean basal mIPSC frequencies in CeA neurons $(n=29)$ from morphine-withdrawn rats were significantly increased $(p<0.01)$ compared to neurons ( $n=25$ ) from placebo (morphine naïve) rats. (C) There was no significant difference in the mean basal mIPSC amplitude between CeA neurons from placebo and morphine withdrawn rats. The statistical significance $^{* *} p<0.01$

main effect of the pellet treatment $\left[F_{(1,18)}=0.5, p>0.05\right]$ nor acute morphine $\times$ pellet treatment interaction $\left[F_{(1,18)}=0.1\right.$, $p>0.05]$ on the mIPSC amplitudes. The comparison of the inhibitory effects of acute morphine on the mIPSCs between placebo and morphine WD rats showed a significant main effect of acute morphine $\left[F_{(1,26)}=21.9, p<0.01\right]$ and pellet treatment $\left[F_{(1,26)}=6.3, p<0.05\right]$ on mIPSC frequencies but no interaction between acute morphine and pellet treatment $\left[F_{(1,26)}=2.4, p>0.05\right]$. Similarly, we found a significant main effect of acute morphine $\left[F_{(1,26)}=34.5, p<0.01\right]$ and pellet treatment $\left[F_{(1,26)}=5.1, p<0.05\right]$ on mIPSC amplitudes associated with no interaction between acute morphine and pellet treatment $\left[F_{(1,26)}=0.7, p>0.05\right]$. Acute morphine had no effect on either the frequency or amplitude in the remaining 1 cell from placebo or 5 cells from morphine WD rats (data not shown). These results suggest that regardless of their previous morphine exposure, some CeA neurons adapt to prolonged $(<8 \mathrm{~h})$ exposure to naloxone during an induction of naloxone-precipitated withdrawal, by reversing the inhibitory effects of the acute morphine on GABAergic transmission. The results are summarized in Table 1.

\section{SIGNALING PATHWAYS INVOLVED IN MORPHINE AND WITHDRAWAL EFFECTS}

We hypothesized that the observed mixed effects of acute morphine on GABAergic transmission in the CeA are caused by a difference in coupling of MORs to G protein subunits, resulting in activation instead of inhibition of the cyclic AMP (cAMP) pathway. To test this possible mechanism, we pre-incubated CeA

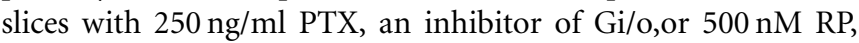
the cAMP signaling inhibitor. In CeA of placebo rats, the PTX ( $n=9$ cells from 4 rats) or RP ( $n=16$ cells from 4 rats) pretreatments had no significant effects on basal mIPSC frequencies $\left[F_{(2,49)}=0.2, p>0.05\right]$ or amplitudes $\left[F_{(2,49)}=1.3, p>0.05\right]$, compared to the untreated CeA neurons (Figure 3). These data suggest that PTX-sensitive Gi/o signaling and cAMP-PKA signaling are not critically involved in the basal GABAergic transmission in the CeA of the placebo rats during prolonged naloxone exposure.

In the morphine $\mathrm{WD}$ rats, there were significant differences in the basal mean frequency $\left[F_{(2,47)}=10, p<0.01\right]$ and amplitude $\left[F_{(2,36)}=12.3, p<0.01\right]$ between PTX-, RP-pretreated and untreated $\mathrm{CeA}$ neurons. We found a significant reduction (Bonferoni test, $p<0.05$ ) of the mIPSC frequencies in CeA neurons pretreated with PTX $(0.3 \pm 0.07 \mathrm{pA}, n=6$ cells from 4 rats) or RP $(0.4 \pm 0.05 \mathrm{pA}, n=13$ cells from 6 rats $)$ compared to the untreated CeA cells (Figure 3). The Bonferroni's post-hoc test showed a significant decrease in the mean mIPSC amplitudes following RP $(46.4 \pm 4.2 \mathrm{pA})$ but not PTX pretreatment $(51.3 \pm 5.1 \mathrm{pA})$ compared to untreated CeA neurons $(66.9 \pm$ $3.4 \mathrm{pA}, n=29 ; p<0.05)$. These findings suggest that both Gi/oand activated cAMP-PKA signaling pathways are involved in the modulation of increased presynaptic GABA release, whereas activated cAMP-PKA signaling may be involved also in the postsynaptic regulation of GABAergic transmission in the CeA during naloxone-precipitated withdrawal.

After pre-incubation of CeA slices with RP for 15-30 min, acute morphine significantly decreased the mean mIPSC frequencies $\left[F_{(1,37)}=16.23, p<0.05\right]$ and amplitudes $\left[F_{(1,37)}=5.8\right.$, $\left.p<0.05 ; t_{(10)}=12.5, p<0.05\right]$ in 10 of $15 \mathrm{CeA}$ neurons from 4 placebo rats (frequency: $62.2 \pm 5.7 \%$ of baseline; amplitude: $87.1 \pm 4.6 \%$ of baseline) and 9 of 15 neurons from $6 \mathrm{WD}$ rats (frequency: $63.8 \pm 3.8 \%$ of baseline; amplitude: $95.1 \pm 5.7 \%$ of baseline; Figures 4A-C). There was no significant main effect of pellet treatment or interaction between acute morphine and pellet treatment. In placebo rats, there were no significant effects of acute morphine on the mIPSCs in 4 cells, and no potentiation of the mIPSC frequency and amplitude in one neuron. In the rest of the CeA neurons ( 4 of 13 cells) from WD rats, acute morphine had no significant effects on mIPSC frequency or amplitude. Thus, $\mathrm{RP}$ pre-incubation prevented the CeA neurons from responding to acute morphine with increases in mIPSCs in placebo (Chisquare test, $p<0.05$ ) or WD (Chi-square test, $p<0.05$ ) rats (Figure 4D). These results suggest that activation of the cAMP signaling pathway plays a key role in the acute morphine-induced increase in the CeA GABAergic transmission in a subpopulation of CeA neurons, and also may be involved in the acute morphine effects mediated via postsynaptic mechanisms in both placebo and morphine WD rats. 
A

\section{Inhibition}

Placebo

Baseline

Acute Morphine

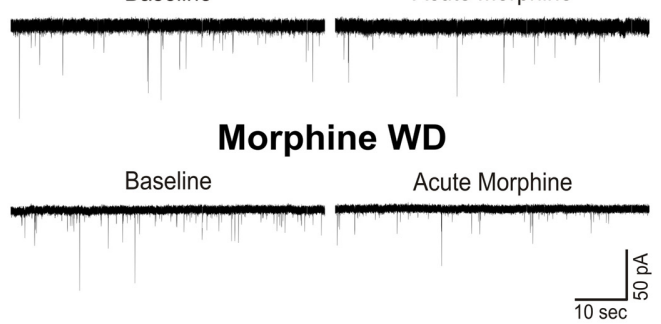

B

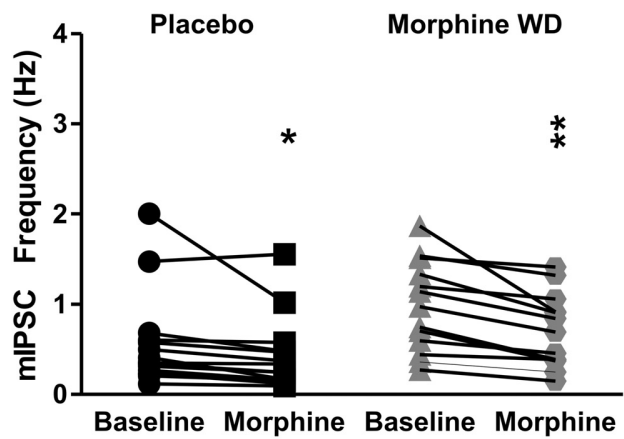

C

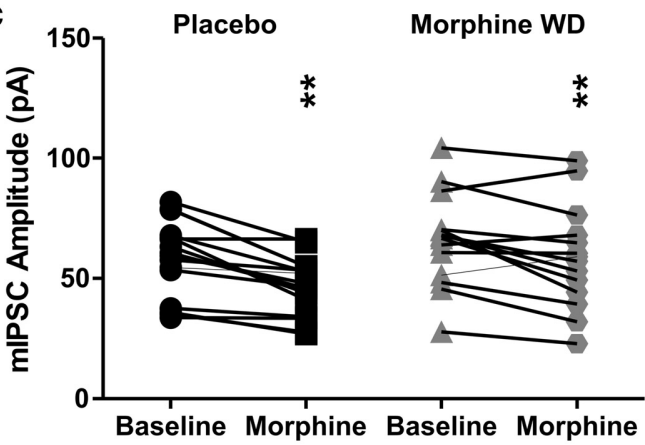

G

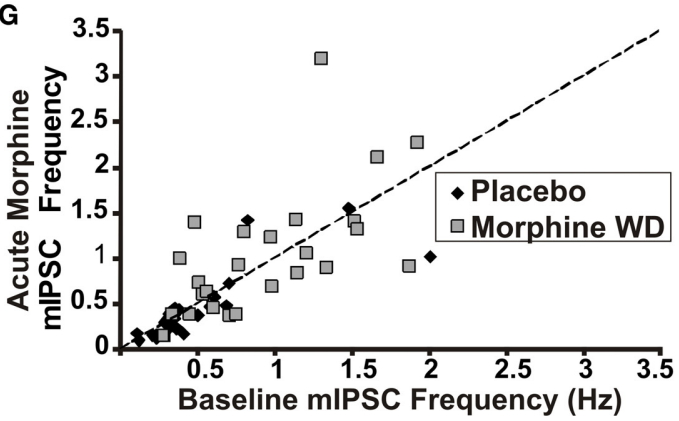

FIGURE 2 | Acute morphine has mixed effects on GABAergic transmission in the CeA following naloxone-precipitated withdrawal. (A) Representative recordings from the $\mathrm{CeA}$ neurons responding to acute morphine $(10 \mu \mathrm{M})$ application by an inhibition of mISPCs from placebo (top panel) and morphine withdrawn (bottom panel) rats. (B,C) In $64 \%$ of neurons from placebo and $45 \%$ from morphine-withdrawn rats, acute morphine decreased the frequency and amplitude of the mIPSCs. (D) Representative recordings of $\mathrm{CeA}$ neurons from placebo and morphine-withdrawn rats that
D

\section{Potentiation}

Placebo

Baseline Acute Morphine

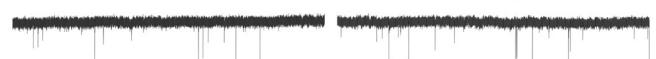

\section{Morphine WD}

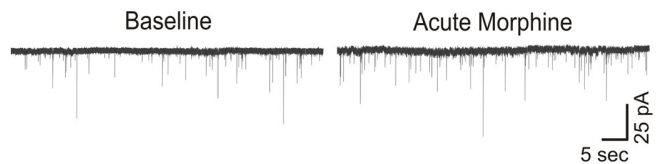

E
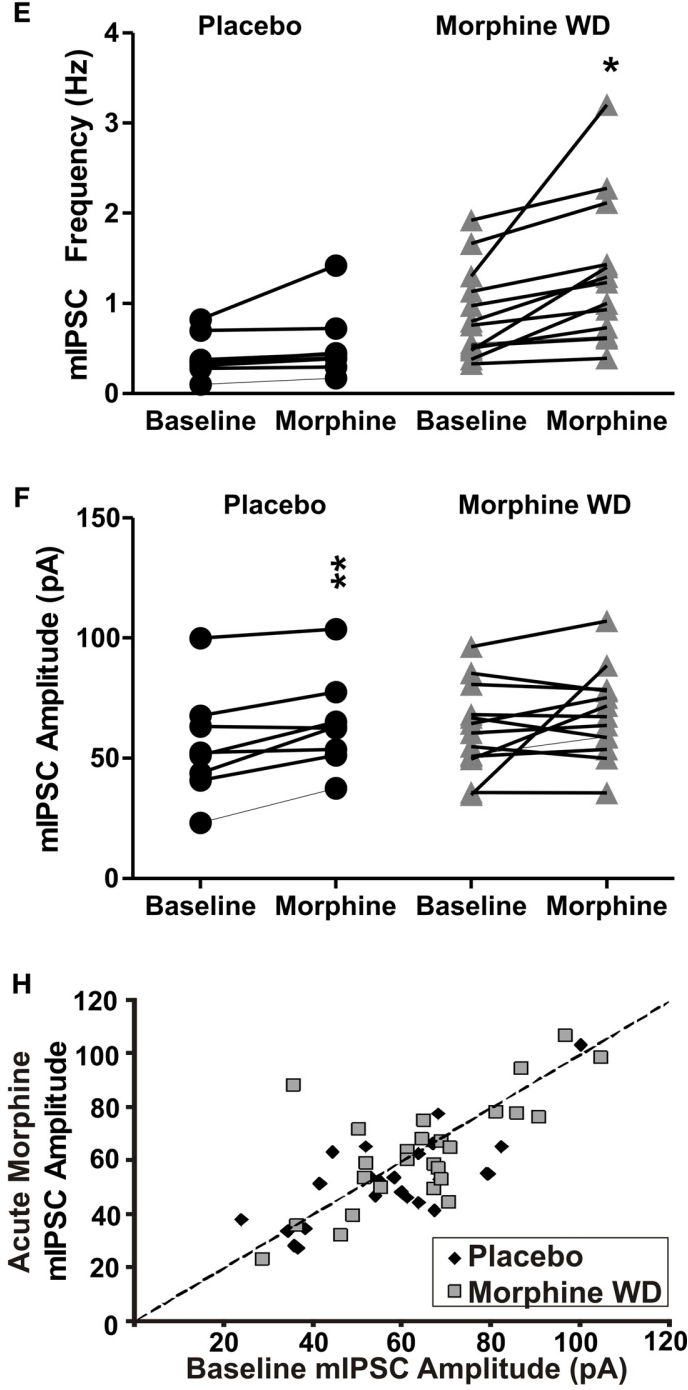

responded to acute morphine by an increase in the mIPSCs. (E,F) Whereas $32 \%$ of $\mathrm{CeA}$ neurons from placebo rats responded to acute morphine by an increase in $\mathrm{mIPSC}$ amplitudes, $41 \%$ of neurons from morphine-withdrawn rats responded to acute morphine by an increase in the mIPSC frequencies. $(\mathbf{G}, \mathbf{H})$ 2-D scatter graphs showing distribution of baseline ( $x$-axis) and acute morphine (y-axis) mIPSC frequencies $(\mathbf{G})$ and amplitudes $(\mathbf{H})$ of individual acute morphine-responsive CeA neurons. The statistical significance * and ${ }^{* *}$ were set at $p<0.05$ and at $p<0.01$, respectively. 
Table 1 | Summary of acute morphine-induced changes in mIPSCs in CeA neurons of placebo and morphine (WD) pellet-treated rats.

\begin{tabular}{lccccc}
\hline Pellet & \multicolumn{2}{c}{ Basal mIPSCs } & & \multicolumn{2}{c}{ Acute Morphine (10 $\mu \mathbf{M})$} \\
\cline { 2 - 3 } treatment & $\begin{array}{c}\text { Frequency } \\
\text { (Hz) }\end{array}$ & $\begin{array}{c}\text { Amplitude } \\
\text { (pA) }\end{array}$ & & $\begin{array}{c}\text { Frequency } \\
\text { (Hz) }\end{array}$ & $\begin{array}{c}\text { Amplitude } \\
\text { (pA) }\end{array}$ \\
\hline Placebo & $0.52 \pm 0.09$ & $57.9 \pm 3.6$ & & $\downarrow$ & $\uparrow$ and $\downarrow$ \\
WD & $0.91 \pm 0.09^{*}$ & $66.4 \pm 3.4$ & & $\uparrow$ and $\downarrow$ & $\downarrow$ \\
\hline
\end{tabular}

*Significant difference between placebo and WD rats; $\downarrow$, significant decrease; $\uparrow$, significant increase.

As PTX is an inhibitor of Gi/o, we expected to prevent the acute morphine-induced decrease in the amplitudes and/or frequencies of CeA mIPSCs. Surprisingly, PTX pre-incubation did not completely prevent acute morphine-induced inhibition or enhancement of CeA mIPSCs from placebo or morphine WD rats. In placebo rats, acute morphine decreased mean mIPSC frequencies or amplitude in 4 of 9 neurons, as determined by the Kolmogorov-Smirnoff test for individual cells (data not shown). Similarly, acute morphine application increased the amplitude or frequency of mIPSCs in an additional 4 cells. In WD rats, PTX also did not prevent the acute morphine reduction or enhancement of the mIPSCs: 2 of 6 neurons still showed increased mean frequencies ( $178.0 \pm 29.4 \%$ of baseline, $n=2$ from 2 rats) or 3 neurons showed decreases in both frequency $(71.0 \%$ of baseline, $n=3$ from 3 rats) and amplitude ( $82.2 \%$ of baseline) of the mIPSCs, respectively (data not shown). These findings suggest that in addition to a PTX-sensitive Gi/o pathway, other PTX-insensitive mechanisms may be involved in the inhibitory effects of acute morphine on GABAergic transmission in the CeA.

\section{DISCUSSION}

In this study, we assessed neuronal adaptations of the GABAergic and opioid systems in the CeA during naloxone-precipitated morphine withdrawal. We found increased CeA basal GABA release in morphine dependent rats during naloxone-precipitated withdrawal. Acute morphine application had mixed effects on the GABAergic transmission in the CeA neurons in this model of naloxone-induced morphine withdrawal. Our study also showed that a continuous exposure to naloxone during the naloxoneprecipitated WD does not prevent acute morphine-induced modulation of GABAergic transmission. Under our experimental conditions, the acute morphine-induced inhibition of GABAergic transmission is very likely mediated by PTX-insensitive mechanisms in many CeA neurons, but we cannot rule out the possibility that a PTX-sensitive mechanism is involved in some CeA neurons as well. On the other hand, an activated cAMP signaling pathway is a likely molecular mechanism underlying the increase in basal GABAergic transmission and acute morphine-induced potentiation of GABAergic transmission in the CeA.

To model the naloxone-precipitated morphine withdrawal, we performed all recordings with naloxone and naloxone plus morphine co-application in the bath during recordings from the CeA neurons from the placebo and morphine WD rats, respectively. It has been shown that there is a tonic inhibition of GABAergic transmission mediated by MORs in the CeA. In addition, acute

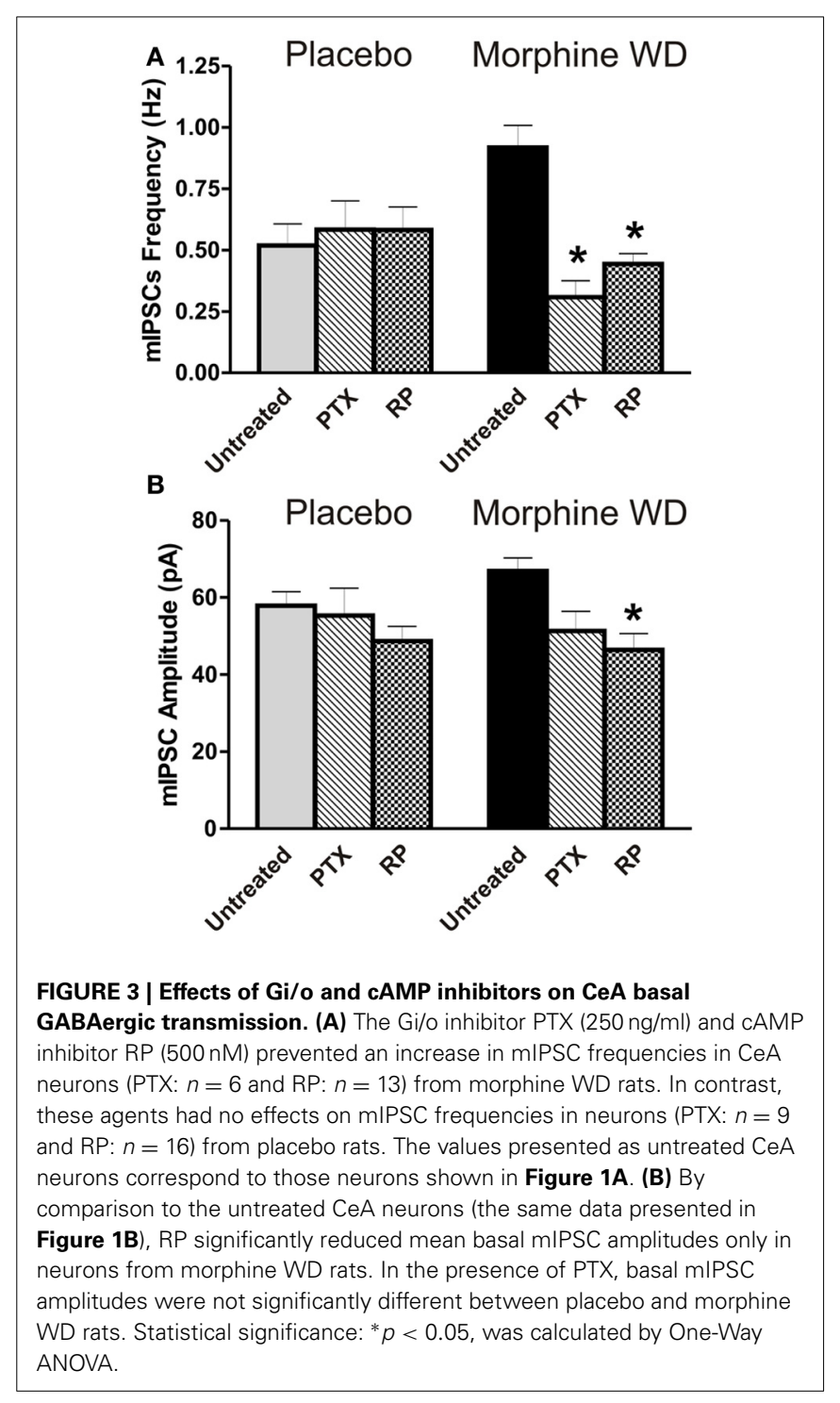

application of MOR antagonists prevents the effects of acute MOR agonists on GABAergic transmission (Zhu and Pan, 2004; Finnegan et al., 2005; Kang-Park et al., 2009; Bajo et al., 2011). Thus, our findings that acute morphine modulates GABAergic transmission in the CeA despite the presence of naloxone in the bath may suggest an incomplete inhibition of the CeA opioid system by naloxone or development of tolerance to naloxone during the naloxone-precipitated withdrawal. Similarly, previous studies have shown attenuation of naloxone-precipitated withdrawal symptoms by inhibition of enkephalinase activity (suggesting an increase in endogenous enkephalin levels; (Haffmans and Dzoljic, 1987; Haffmans et al., 1987) and induced heroin reinstatement during naloxone-precipitated WD by a priming injection of heroin (Shaham et al., 1996). Mechanisms underlying these paradoxical findings may involve both opioid-dependent and non-opioid-dependent (e.g., activation of glia via toll-like receptor 4) (Hutchinson et al., 2007, 2012; Watkins et al., 2009; Lewis et al., 2012) mechanisms. With regard to opioid dependent mechanisms, we hypothesize that a prolonged naloxone exposure 


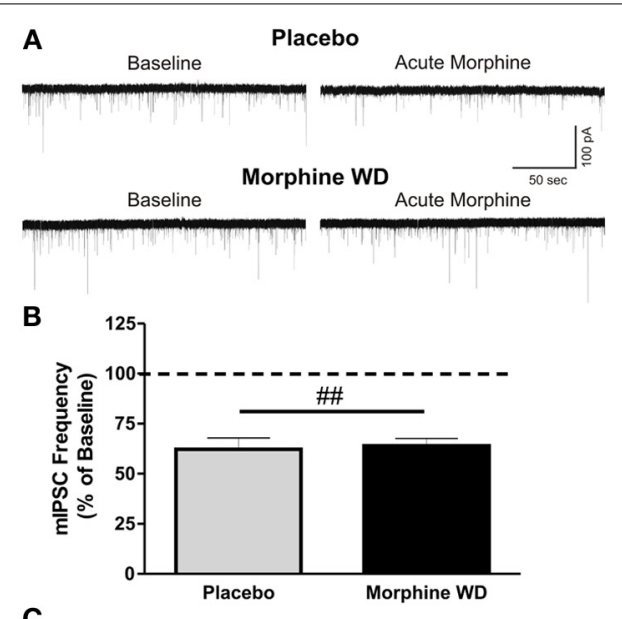

C

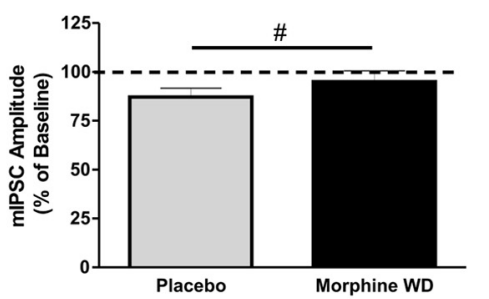

D

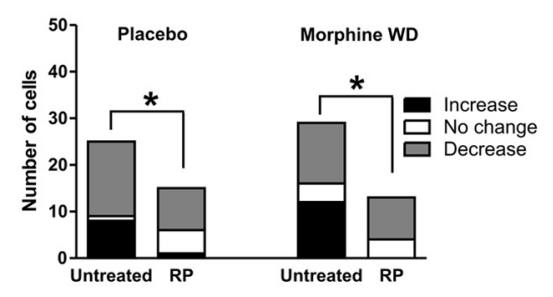

FIGURE 4 | RP inhibition of cAMP prevents enhancement of GABAergic transmission induced by acute morphine application. (A) Representative recordings from $\mathrm{CeA}$ neurons from placebo and morphine WD rats pre-treated with RP. (B) After RP $(500 \mathrm{nM})$ pre-treatment, acute morphine $(10 \mu \mathrm{M})$ gave a significant main inhibitory effect on mean mIPSC frequencies and amplitudes (C) of CeA neurons from placebo $(n=10)$ and morphine-withdrawn $(n=9)$ rats. Statistical significance ${ }^{\#} p<0.05$ and \#\# $p<0.01$ ) was calculated by Two-Way ANOVA. (D) In CeA from both placebo and WD rats, RP-pretreatment significantly reduced the number of CeA neurons responding to acute morphine by an increase in mIPSCs, as calculated by Chi-square test $\left({ }^{*} p<0.05\right)$.

(more than $1 \mathrm{~h}$ ) could lead to a continuous blockade of the MOR-dependent tonic inhibition of GABAergic transmission and elicit tolerance and/or adaptation of the CeA opioid system. Changes in messaging pathways, especially in cAMP and PKA signaling, and perhaps $\mathrm{Gz}$ activation as well, may develop under the continuous presence of naloxone and thus mediate the acute morphine modulation of the GABAergic transmission.

The effects of naloxone on the opioid system are determined by a previous opioid treatment. Naloxone acts as a neutral agonist in MOR/DOR agonist-naïve cells cultures and as an inverse agonist after a previous MOR/DOR exposure (Wang et al., 2001). Thus, our findings of increased basal GABA release in some CeA neurons from the morphine $\mathrm{WD}$ rats compared to placebo rats may support the idea of naloxone acting as an inverse agonist in the morphine $\mathrm{WD}$ rats or as a neutral antagonist in the $\mathrm{CeA}$ in placebo rats. The increased GABA release in the CeA during naloxone-precipitated withdrawal is in accord with the enhanced GABAergic synaptic transmission found in other brain regions after such naloxone induced WD (Bonci and Williams, 1997; Chieng and Williams, 1998; Ingram et al., 1998; Jolas et al., 2000; Hack et al., 2003; Madhavan et al., 2010a,b). Our group (Bajo et al., 2008, 2009) and others (Madhavan et al., 2010a; Meye et al., 2012) reported that acute morphine increases GABAergic transmission during spontaneously-morphine WD rats and naloxone-precipitated withdrawal combined with recordings without naloxone showed similar inverse effects of acute MOR agonists on GABAergic transmission during morphine withdrawal. Overall, these findings indicate that MOR-induced potentiation of GABAergic transmission during morphine withdrawal is a general neuroadaptive mechanism associated with morphine withdrawal. However, a role for non-opioid mechanisms cannot be ruled out and require further investigation.

The molecular mechanism of both the action-potential independent increase in GABA release and the morphine-induced potentiation of GABAergic transmission in the CeA appears to be mediated by a hyperactivation of cAMP, because RP pretreatment decreased the mean frequencies of basal mIPSCs and prevented the acute morphine enhancement of GABAergic transmission. There are numerous studies reporting a compensatory increase in $\mathrm{PGE}_{1}$ - or forskolin-stimulated adenylyl cyclase activity in neuronal cells chronically exposed to opioids upon removal of the opioids (Bailey and Connor, 2005; Williams et al., 2013). A superactivation of cAMP also has been reported to mediate DAMGO-induced enhancement of GABA transmission in the VTA (Madhavan et al., 2010a; Meye et al., 2012). In general, the excitatory effects occurring during opioid tolerance and dependence is thought to be mediated by an additive or synergistic effect of a loss of adenylyl cyclase inhibition by Gi/o and stimulation of adenylyl cyclases by both Gs and its associated $G \beta \gamma$ (Wang and Burns, 2006). Thus, we assume that both mechanisms, a switch in MOR G protein coupling from cAMP-inhibitory Gi/o to cAMP-stimulatory Gs (Crain and Shen, 1998; Wang et al., 2005) and a stimulation of adenylyl cyclase by G $\beta \gamma$ subunits, may mediate superactivation of cAMP during morphine withdrawal in the CeA. It has been shown that chronic morphine treatment maintains the association of Gs with MORs and diminishes the association of Gi/o with MORs (Chakrabarti et al., 2005; Wang and Burns, 2006). Studies on cell cultures also showed that chronic morphine-induced interaction of $G \beta \gamma$ with adenylyl cyclase can occur without alteration of the $G$ protein coupling profile (Chakrabarti et al., 2001). These findings support the hypothesis that both of these events can contribute to enhanced activation of the cAMP following chronic morphine treatment (Wang et al., 2005; Wang and Burns, 2006). The chronic morphine treatment-induced reduction of MOR-Gi/o coupling, paralleled with increased Gs coupling and a direct interaction of $\mathrm{G} \beta \gamma$ with adenylate cyclase, has been found in the striatum, periaqueductal gray, and spinal cord (Kitanaka et al., 2008).

MORs preferentially couple to the PTX-sensitive G proteins, Gi, and Go, to inhibit the adenylyl cyclase/cAMP pathway (Connor and Christie, 1999). We found that Gi/o plays a role 
in the action potential-independent GABA release in CeA, as PTX pre-treatment reduced the mean frequencies of mIPSCs in the CeA neurons from morphine WD rats but had no effects in placebo rats. This concurs with studies in cultured cell lines showing opioid-induced adenylyl cyclase superactivation that was sensitive to PTX treatment, implicating the involvement of PTXsensitive $\mathrm{Gi} /$ o proteins in mediating these adaptive responses (Tso and Wong, 2000; Steiner et al., 2005). Another possibility may include a PTX-pretreatment induced substitution of Gi/o by Gz. Despite a similarity in inhibition of adenylyl cyclase and $\mathrm{K}^{+}$channels, $\mathrm{Gz}$ exhibits unique biochemical,and regulatory properties (Ho and Wong, 2001) that may underlie the decrease in basal mIPSCs observed in the CeA of WD rats. Our results showing acute morphine-induced reduction of GABAergic transmission following PTX-pre-treatment of the CeA slices suggest that both PTX-sensitive as well as PTX-insensitive mechanisms, such as Gz or G $\beta \gamma$ subunits, may be involved in the inhibitory effects of acute morphine on GABAergic transmission in the CeA. MORs have been reported to modulate both PTX-sensitive Gi/oproteins as well as the PTX-insensitive Gz proteins (Sanchez-Blazquez et al., 2000). Gz also inhibits adenylyl cyclase (Sadana and Dessauer, 2009) and is thought to be involved in the regulation of ion channel activities and exocytosis (Ho and Wong, 2001). Morphine is a strong activator of Gz (Garzon et al., 1998), and the antinociceptive activity of morphine (Sanchez-Blazquez et al., 2001; Garzon et al., 2011) and analgesic desensitization are strongly decreased after $\mathrm{Gz}$ depletion (Garzon et al., 2009). As Gz is expressed in the amygdala (Carrasco et al., 2004), findings of alleviated morphine dependence and subsequent naloxone-precipitated withdrawal syndrome following intracerebroventricular administration of a Gz-specific antiserum (Sanchez-Blazquez and Garzon, 1994) suggest a potential involvement of $\mathrm{Gz}$ in opioid signaling in the CeA during morphine withdrawal.

The overall effects of chronic morphine exposure in a given CeA neuron may also depend on the presence of particular AC isoforms in those cells (Avidor-Reiss et al., 1997; Watts and Neve, 2005). Most cells express two or more AC isoforms and nearly all AC isoforms are expressed in the brain (Sadana and Dessauer, 2009). In general, a chronic treatment followed by agonist withdrawal has been shown to increase the activity of AC-I, AC-V, $\mathrm{AC}-\mathrm{VI}$, and AC-VIII isoforms, while reducing activity of the AC-II, IV, and VII isoforms (Sunahara and Taussig, 2002). In morphine dependence, an upregulation of AC signal transduction components is found in brain regions associated with drug reinforcement and withdrawal (Sadana and Dessauer, 2009), and is mediated by the AC-I, V, VI, and VIII isoforms (Avidor-Reiss et al., 1997; Chakrabarti et al., 2001). By contrast, an overexpression of ACVII results in enhanced acute and chronic actions of morphine, and leads to more rapid development of tolerance (Yoshimura et al., 2000).

In summary, these results indicate a cell-specific neuroadaptation to chronic morphine treatment of the opioid system and its effects on GABAergic transmission in CeA neurons. The cell-type specific responses to acute morphine application during chronic morphine treatment and morphine WD raise several questions: (1) What afferent projections and what CeA neuronal populations undergo neuroadaptive changes during the transition period leading to development of morphine dependence? (2) What mechanisms are regulating these chronic morphine-induced circuitry- and cell-specific neuroadaptative changes in the CeA? (3) What particular neuroadaptive changes of the opioid and neurotransmitter systems in the CeA play a critical role in development of morphine dependence and withdrawal? To address these issues, further studies will be required, focusing on characterization of cell types, circuitries, afferent projections and their targeted CeA neurons with regard to their neurotransmitter, neuropeptide, and cAMP contents.

\section{ACKNOWLEDGMENTS}

We would like to thank Dr. Varodayan for her help with some data collection. This work was supported by grants from the National Institute on Drug Abuse [DA03665], and the National Institute on Alcohol Abuse and Addiction Integrative Neuroscience Initiative on Alcoholism [UO1 AA013498].

\section{REFERENCES}

Avidor-Reiss, T., Nevo, I., Saya, D., Bayewitch, M., and Vogel, Z. (1997). Opiateinduced adenylyl cyclase superactivation is isozyme-specific. J. Biol. Chem. 272, 5040-5047. doi: 10.1074/jbc.272.8.5040

Bailey, C. P., and Connor, M. (2005). Opioids: cellular mechanisms of tolerance and physical dependence. Curr. Opin. Pharmacol. 5, 60-68. doi: 10.1016/j.coph.2004.08.012

Bajo, M., Crawford, E. F., Roberto, M., Madamba, S. G., and Siggins, G. R. (2006). Chronic morphine treatment alters expression of N-methyl-D-aspartate receptor subunits in the extended amygdala. J. Neurosci. Res. 83, 532-537. doi: 10.1002/jnr.20756

Bajo, M., Madamba, S. G., and Siggins, G. R. (2008). Effects of Morphine Withdrawal on Membrane and Gabaergic Synaptic Properties of Central Amygdala Neurons. Washington, DC: Program No. 765.11. 2008 Neuroscience Meeting Planner.

Bajo, M., Madamba, S. G., and Siggins, G. R. (2009). Reversal of Acute Mu Opioid Agonist Effects on GABAergic Transmission in Central Amygdala Following Morphine Withdrawal. Chicago, IL: Program No. 255.14. 2009 Neuroscience Meeting Planner.

Bajo, M., Roberto, M., Madamba, S. G., and Siggins, G. R. (2011). Neuroadaptation of GABAergic transmission in the central amygdala during chronic morphine treatment. Addict. Biol. 16, 551-564. doi: 10.1111/j.1369-1600.2010. 00269.x

Befort, K., Filliol, D., Ghate, A., Darcq, E., Matifas, A., Muller, J., et al. (2008). $\mathrm{Mu}$-opioid receptor activation induces transcriptional plasticity in the central extended amygdala. Eur. J. Neurosci. 27, 2973-2984. doi: 10.1111/j.14609568.2008.06273.x

Bie, B., Zhu, W., and Pan, Z. Z. (2009). Rewarding morphine-induced synaptic function of delta-opioid receptors on central glutamate synapses. J. Pharmacol. Exp. Ther. 329, 290-296. doi: 10.1124/jpet.108.148908

Bonci, A., and Williams, J. T. (1997). Increased probability of GABA release during withdrawal from morphine. J. Neurosci. 17, 796-803.

Carrasco, G. A., Damjanoska, K. J., D’Souza, D. N., Zhang, Y., Garcia, F., Battaglia, G., et al. (2004). Short-term cocaine treatment causes neuroadaptive changes in Galphaq and Galpha11 proteins in rats undergoing withdrawal. J. Pharmacol. Exp. Ther. 311, 349-355. doi: 10.1124/jpet.104.069807

Cassell, M. D., Freedman, L. J., and Shi, C. (1999). The intrinsic organization of the central extended amygdala. Ann. N.Y. Acad. Sci. 877, 217-241. doi: 10.1111/j.1749-6632.1999.tb09270.x

Chakrabarti, S., Oppermann, M., and Gintzler, A. R. (2001). Chronic morphine induces the concomitant phosphorylation and altered association of multiple signaling proteins: a novel mechanism for modulating cell signaling. Proc. Natl. Acad. Sci. U.S.A. 98, 4209-4214. doi: 10.1073/pnas.071031798

Chakrabarti, S., Regec, A., and Gintzler, A. R. (2005). Biochemical demonstration of mu-opioid receptor association with Gsalpha: enhancement following morphine exposure. Brain Res. Mol. Brain Res. 135, 217-224. doi: 10.1016/j.molbrainres.2004.12.016 
Chieng, B., and Williams, J. T. (1998). Increased opioid inhibition of GABA release in nucleus accumbens during morphine withdrawal. J. Neurosci. 18, 7033-7039.

Chieng, B. C., Christie, M. J., and Osborne, P. B. (2006). Characterization of neurons in the rat central nucleus of the amygdala: Cellular physiology, morphology, and opioid sensitivity. J. Comp. Neurol. 497, 910-927. doi: $10.1002 /$ cne. 21025

Christie, M. J. (2008). Cellular neuroadaptations to chronic opioids: tolerance, withdrawal and addiction. Br. J. Pharmacol. 154, 384-396. doi: 10.1038/bjp.2008.100

Clark, M. J., Furman, C. A., Gilson, T. D., and Traynor, J. R. (2006). Comparison of the relative efficacy and potency of mu-opioid agonists to activate Galpha(i/o) proteins containing a pertussis toxin-insensitive mutation. J. Pharmacol. Exp. Ther. 317, 858-864. doi: 10.1124/jpet.105.096818

Connor, M., and Christie, M. D. (1999). Opioid receptor signalling mechanisms. Clin. Exp. Pharmacol. Physiol. 26, 493-499. doi: 10.1046/j.14401681.1999.03049.x

Crain, S. M., and Shen, K. F. (1998). Modulation of opioid analgesia, tolerance and dependence by Gs-coupled, GM1 ganglioside-regulated opioid receptor functions. Trends Pharmacol. Sci. 19, 358-365. doi: 10.1016/S0165-6147(98)01241-3

Criner, S. H., Liu, J., and Schulteis, G. (2007). Rapid neuroadaptation in the nucleus accumbens and bed nucleus of the stria terminalis mediates suppression of operant responding during withdrawal from acute opioid dependence. Neuroscience 144, 1436-1446. doi: 10.1016/j.neuroscience.2006.11.002

Finnegan, T. F., Chen, S. R., and Pan, H. L. (2005). Effect of the $\{\mathrm{mu}\}$ opioid on excitatory and inhibitory synaptic inputs to periaqueductal grayprojecting neurons in the amygdala. J. Pharmacol. Exp. Ther. 312, 441-448. doi: 10.1124/jpet.104.074633

Finnegan, T. F., Chen, S. R., and Pan, H. L. (2006). Mu opioid receptor activation inhibits GABAergic inputs to basolateral amygdala neurons through Kv1.1/1.2 channels. J. Neurophysiol. 95, 2032-2041. doi: 10.1152/jn.01004.2005

Frenois, F., Cador, M., Caille, S., Stinus, L., and Le Moine, C. (2002). Neural correlates of the motivational and somatic components of naloxone-precipitated morphine withdrawal. Eur. J. Neurosci. 16, 1377-1389. doi: 10.1046/j.14609568.2002.02187.x

Garzon, J., Castro, M., and Sanchez-Blazquez, P. (1998). Influence of Gz and Gi2 transducer proteins in the affinity of opioid agonists to mu receptors. Eur. J. Neurosci. 10, 2557-2564. doi: 10.1046/j.1460-9568.1998.00267.x

Garzon, J., de la Torre-Madrid, E., Rodriguez-Munoz, M., Vicente-Sanchez, A., and Sanchez-Blazquez, P. (2009). Gz mediates the long-lasting desensitization of brain CB1 receptors and is essential for cross-tolerance with morphine. Mol. Pain 5, 11. doi: 10.1186/1744-8069-5-11

Garzon, J., Rodriguez-Munoz, M., Vicente-Sanchez, A., Bailon, C., MartinezMurillo, R., and Sanchez-Blazquez, P. (2011). RGSZ2 binds to the neural nitric oxide synthase PDZ domain to regulate mu-opioid receptor-mediated potentiation of the N-methyl-D-aspartate receptor-calmodulin-dependent protein kinase II pathway. Antioxid. Redox Signal. 15, 873-887. doi: 10.1089/ars.2010.3767

Gold, L. H., Stinus, L., Inturrisi, C. E., and Koob, G. F. (1994). Prolonged tolerance, dependence and abstinence following subcutaneous morphine pellet implantation in the rat. Eur. J. Pharmacol. 253, 45-51. doi: 10.1016/00142999(94)90755-2

Hack, S. P., Vaughan, C. W., and Christie, M. J. (2003). Modulation of GABA release during morphine withdrawal in midbrain neurons in vitro. Neuropharmacology 45, 575-584. doi: 10.1016/S0028-3908(03)00205-3

Haffmans, J., and Dzoljic, M. R. (1987). Inhibition of enkephalinase activity attenuates naloxone-precipitated withdrawal symptoms. Gen. Pharmacol. 18, 103-105. doi: 10.1016/0306-3623(87)90179-0

Haffmans, J., Walsum, M. V., van Amsterdam, J. C., and Dzoljic, M. R. (1987). Phelorphan, an inhibitor of enzymes involved in the biodegradation of enkephalins, affected the withdrawal symptoms in chronic morphinedependent rats. Neuroscience 22, 233-236. doi: 10.1016/0306-4522(87)90213-2

Heimer, L., and Alheid, G. F. (1991). Piecing together the puzzle of basal forebrain anatomy. Adv. Exp. Med. Biol. 295, 1-42. doi: 10.1007/978-1-4757-0145-6_1

Ho, M. K., and Wong, Y. H. (2001). G(z) signaling: emerging divergence from G(i) signaling. Oncogene 20, 1615-1625. doi: 10.1038/sj.onc. 1204190

Hutchinson, M. R., Bland, S. T., Johnson, K. W., Rice, K. C., Maier, S. F., and Watkins, L. R. (2007). Opioid-induced glial activation: mechanisms of activation and implications for opioid analgesia, dependence, and reward. ScientificWorldJournal 7, 98-111. doi: 10.1100/tsw.2007.230
Hutchinson, M. R., Northcutt, A. L., Hiranita, T., Wang, X., Lewis, S. S., Thomas, J., et al. (2012). Opioid activation of toll-like receptor 4 contributes to drug reinforcement. J. Neurosci. 32, 11187-11200. doi: 10.1523/JNEUROSCI.068412.2012

Ingram, S. L., Vaughan, C. W., Bagley, E. E., Connor, M., and Christie, M. J. (1998). Enhanced opioid efficacy in opioid dependence is caused by an altered signal transduction pathway. J. Neurosci. 18, 10269-10276.

Jin, C., Araki, H., Nagata, M., Suemaru, K., Shibata, K., Kawasaki, H., et al. (2004). Withdrawal-induced c-Fos expression in the rat centromedial amygdala $24 \mathrm{~h}$ following a single morphine exposure. Psychopharmacology 175, 428-435. doi: 10.1007/s00213-004-1844-4

Jolas, T., Nestler, E. J., and Aghajanian, G. K. (2000). Chronic morphine increases GABA tone on serotonergic neurons of the dorsal raphe nucleus: association with an up-regulation of the cyclic AMP pathway. Neuroscience 95, 433-443. doi: 10.1016/S0306-4522(99)00436-4

Kang-Park, M. H., Kieffer, B. L., Roberts, A. J., Roberto, M., Madamba, S. G., Siggins, G. R., et al. (2009). Mu-opioid receptors selectively regulate basal inhibitory transmission in the central amygdala: lack of ethanol interactions. J. Pharmacol. Exp. Ther. 328, 284-293. doi: 10.1124/jpet.108.140749

Kirschke, C., Schadrack, J., Zieglgansberger, W., and Spanagel, R. (2002). Effects of morphine withdrawal on micro-opioid receptor-stimulated guanylyl 5'-[gamma-[35S]thio]-triphosphate autoradiography in rat brain. Eur. J. Pharmacol. 446, 43-51. doi: 10.1016/S0014-2999(02)01763-6

Kitanaka, N., Kitanaka, J., Hall, F. S., Tatsuta, T., Morita, Y., Takemura, M., et al. (2008). Alterations in the levels of heterotrimeric G protein subunits induced by psychostimulants, opiates, barbiturates, and ethanol: Implications for drug dependence, tolerance, and withdrawal. Synapse 62, 689-699. doi: 10.1002/syn. 20543

Koob, G. F., and Volkow, N. D. (2010). Neurocircuitry of addiction. Neuropsychopharmacology 35, 217-238. doi: 10.1038/npp.2009.110

Laugwitz, K. L., Offermanns, S., Spicher, K., and Schultz, G. (1993). mu and delta opioid receptors differentially couple to $G$ protein subtypes in membranes of human neuroblastoma SH-SY5Y cells. Neuron 10, 233-242. doi: 10.1016/08966273(93)90314-H

Lewis, S. S., Loram, L. C., Hutchinson, M. R., Li, C. M., Zhang, Y., Maier, S. F., et al. (2012). (+)-naloxone, an opioid-inactive toll-like receptor 4 signaling inhibitor, reverses multiple models of chronic neuropathic pain in rats. J. Pain 13, 498-506. doi: 10.1016/j.jpain.2012.02.005

Li, Y. Q., Li, F. Q., Wang, X. Y., Wu, P., Zhao, M., Xu, C. M., et al. (2008). Central amygdala extracellular signal-regulated kinase signaling pathway is critical to incubation of opiate craving. J. Neurosci. 28, 13248-13257. doi: 10.1523/JNEUROSCI.3027-08.2008

Madhavan, A., Bonci, A., and Whistler, J. L. (2010a). Opioid-Induced GABA potentiation after chronic morphine attenuates the rewarding effects of opioids in the ventral tegmental area. J. Neurosci. 30, 14029-14035. doi: 10.1523/JNEUROSCI.3366-10.2010

Madhavan, A., He, L., Stuber, G. D., Bonci, A., and Whistler, J. L. (2010b). Micro-Opioid receptor endocytosis prevents adaptations in ventral tegmental area GABA transmission induced during naloxone-precipitated morphine withdrawal. J. Neurosci. 30, 3276-3286. doi: 10.1523/JNEUROSCI.463409.2010

Maher, C. E., Martin, T. J., and Childers, S. R. (2005). Mechanisms of mu opioid receptor/G-protein desensitization in brain by chronic heroin administration. Life Sci. 77, 1140-1154. doi: 10.1016/j.lfs.2005.03.004

Meye, F. J., van Zessen, R., Smidt, M. P., Adan, R. A., and Ramakers, G. M. (2012). Morphine withdrawal enhances constitutive mu-opioid receptor activity in the ventral tegmental area. J. Neurosci. 32, 16120-16128. doi: 10.1523/JNEUROSCI.1572-12.2012

Neugebauer, V., Li, W., Bird, G. C., and Han, J. S. (2004). The amygdala and persistent pain. Neuroscientist 10, 221-234. doi: 10.1177/1073858403261077

Sadana, R., and Dessauer, C. W. (2009). Physiological roles for G protein-regulated adenylyl cyclase isoforms: insights from knockout and overexpression studies. Neurosignals 17, 5-22. doi: 10.1159/000166277

Sanchez-Blazquez, P., Boronat, M. A., Olmos, G., Garcia-Sevilla, J. A., and Garzon, J. (2000). Activation of I(2)-imidazoline receptors enhances supraspinal morphine analgesia in mice: a model to detect agonist and antagonist activities at these receptors. Br. J. Pharmacol. 130, 146-152. doi: 10.1038/sj.bjp.0703294

Sanchez-Blazquez, P., and Garzon, J. (1994). Antibodies directed against alpha subunits of $\mathrm{Gi}, \mathrm{Gx} / \mathrm{z}, \mathrm{GO}$ and GS transducer proteins reduced the morphine 
withdrawal syndrome in mice. Life Sci. 55, PL445-PL450. doi: 10.1016/00243205(94)90098-1

Sanchez-Blazquez, P., Gomez-Serranillos, P., and Garzon, J. (2001). Agonists determine the pattern of G-protein activation in mu-opioid receptor-mediated supraspinal analgesia. Brain Res. Bull. 54, 229-235. doi: 10.1016/S03619230(00)00448-2

Shaham, Y., Rajabi, H., and Stewart, J. (1996). Relapse to heroin-seeking in rats under opioid maintenance: the effects of stress, heroin priming, and withdrawal. J. Neurosci. 16, 1957-1963.

Sim, L. J., Selley, D. E., Dworkin, S. I., and Childers, S. R. (1996). Effects of chronic morphine administration on mu opioid receptor-stimulated [35S]GTPgammaS autoradiography in rat brain. J. Neurosci. 16, 2684-2692.

Sim-Selley, L. J., Selley, D. E., Vogt, L. J., Childers, S. R., and Martin, T. J. (2000). Chronic heroin self-administration desensitizes mu opioid receptor-activated G-proteins in specific regions of rat brain. J. Neurosci. 20, 4555-4562.

Solecki, W., Ziolkowska, B., Krowka, T., Gieryk, A., Filip, M., and Przewlocki, R. (2009). Alterations of prodynorphin gene expression in the rat mesocorticolimbic system during heroin self-administration. Brain Res. 1255, 113-121. doi: 10.1016/j.brainres.2008.12.002

Steiner, D., Avidor-Reiss, T., Schallmach, E., Butovsky, E., Lev, N., and Vogel, Z. (2005). Regulation of adenylate cyclase type VIII splice variants by acute and chronic Gi/o-coupled receptor activation. Biochem. J. 386, 341-348. doi: 10.1042/BJ20041670

Sun, N., and Cassell, M. D. (1993). Intrinsic GABAergic neurons in the rat central extended amygdala. J. Comp. Neurol. 330, 381-404. doi: 10.1002/cne.903300308

Sunahara, R. K., and Taussig, R. (2002). Isoforms of mammalian adenylyl cyclase: multiplicities of signaling. Mol. Interv. 2, 168-184. doi: 10.1124/mi.2.3.168

Tso, P. H., and Wong, Y. H. (2000). G(z) can mediate the acute actions of muand kappa-opioids but is not involved in opioid-induced adenylyl cyclase supersensitization. J. Pharmacol. Exp. Ther. 295, 168-176.

Veinante, P., and Freund-Mercier, M. J. (1998). Intrinsic and extrinsic connections of the rat central extended amygdala: an in vivo electrophysiological study of the central amygdaloid nucleus. Brain Res. 794, 188-198. doi: 10.1016/S00068993(98)00228-5

Wang, D., Raehal, K. M., Bilsky, E. J., and Sadee, W. (2001). Inverse agonists and neutral antagonists at mu opioid receptor (MOR): possible role of basal receptor signaling in narcotic dependence. J. Neurochem. 77, 1590-1600. doi: 10.1046/j.1471-4159.2001.00362.x

Wang, H. Y., and Burns, L. H. (2006). Gbetagamma that interacts with adenylyl cyclase in opioid tolerance originates from a Gs protein. J. Neurobiol. 66, 1302-1310. doi: 10.1002/neu.20286

Wang, H. Y., Friedman, E., Olmstead, M. C., and Burns, L. H. (2005). Ultralow-dose naloxone suppresses opioid tolerance, dependence and associated changes in mu opioid receptor-G protein coupling and Gbetagamma signaling. Neuroscience 135, 247-261. doi: 10.1016/j.neuroscience.2005.06.003

Watkins, L. R., Hutchinson, M. R., Rice, K. C., and Maier, S. F. (2009). The toll of opioid-induced glial activation: improving the clinical efficacy of opioids by targeting glia. Trends Pharmacol. Sci. 30, 581-591. doi: 10.1016/j.tips.2009. 08.002

Watts, V. J., and Neve, K. A. (2005). Sensitization of adenylate cyclase by Galpha i/o-coupled receptors. Pharmacol. Ther. 106, 405-421. doi: 10.1016/j.pharmthera.2004.12.005

Weller, K. L., and Smith, D. A. (1982). Afferent connections to the bed nucleus of the stria terminalis. Brain Res. 232, 255-270. doi: 10.1016/0006-8993(82) 90272-4

Williams, J. T., Ingram, S. L., Henderson, G., Chavkin, C., von Zastrow, M., Schulz, S., et al. (2013). Regulation of mu-opioid receptors: desensitization, phosphorylation, internalization, and tolerance. Pharmacol. Rev. 65, 223-254. doi: $10.1124 /$ pr.112.005942

Yoshimura, M., Wu, P. H., Hoffman, P. L., and Tabakoff, B. (2000). Overexpression of type 7 adenylyl cyclase in the mouse brain enhances acute and chronic actions of morphine. Mol. Pharmacol. 58, 1011-1016. doi: 10.1124/mol.58. 5.1011

Zhu, W., and Pan, Z. Z. (2004). Synaptic properties and postsynaptic opioid effects in rat central amygdala neurons. Neuroscience 127, 871-879. doi: 10.1016/j.neuroscience.2004.05.043

Zhu, W., and Pan, Z. Z. (2005). Mu-opioid-mediated inhibition of glutamate synaptic transmission in rat central amygdala neurons. Neuroscience 133, 97-103. doi: 10.1016/j.neuroscience.2005.02.004

Conflict of Interest Statement: The authors declare that the research was conducted in the absence of any commercial or financial relationships that could be construed as a potential conflict of interest.

Received: 01 January 2014; accepted: 14 May 2014; published online: 04 June 2014. Citation: Bajo M, Madamba SG, Roberto M and Siggins GR (2014) Acute morphine alters GABAergic transmission in the central amygdala during naloxone-precipitated morphine withdrawal: role of cyclic AMP. Front. Integr. Neurosci. 8:45. doi: 10.3389/ frint.2014.00045

This article was submitted to the journal Frontiers in Integrative Neuroscience. Copyright $\odot 2014$ Bajo, Madamba, Roberto and Siggins. This is an open-access article distributed under the terms of the Creative Commons Attribution License (CC BY). The use, distribution or reproduction in other forums is permitted, provided the original author(s) or licensor are credited and that the original publication in this journal is cited, in accordance with accepted academic practice. No use, distribution or reproduction is permitted which does not comply with these terms. 